\title{
Research on the Influences of Reactive Power Fluctuation of Wind Farm on the System Voltage Stability
}

\author{
Bai Qinyu ${ }^{1, a}$, Zhang Yonggang ${ }^{2, \mathrm{~b}}$, Xu Jun ${ }^{3}$, Chen $\mathrm{Yu}^{4}$ and Zhang Xiaotian ${ }^{5}$ \\ ${ }^{1}$ Electric Power Research Institute of State Grid Liaoning Electric Power Co.,Ltd. China. \\ ${ }^{2}$ State Grid Tongliao Power Supply Company \\ ${ }^{3}$ State Grid Huangshi Electric Power Supply Company \\ ${ }^{4}$ China Satellite Tracking \& Control Department, Yuan Wang 3 \\ ${ }^{5}$ State Grid Liaoning Economic Research Institute \\ aE-mail: winterinse@163.com, ${ }^{\mathrm{a}}$ email: 405324898@qq.com
}

Keywords: Wind farm, Reactive power compensation device, Voltage stability

Abstract. The connection of wind farm causes influence on the power system voltage stability because of the volatility and intermittency of wind power. In this paper, based on researching a regional wind farm, the influence of power fluctuation on power system voltage is analyzed. The influences of different settings of manual (mechanical) switched capacitor, SVC and STATCOM to the improving of power grid voltage are analyzed by PSCAD. Meanwhile, the improvement effects of the power grid voltages with different reactive power compensation devices are calculated by contrasting the curves of bus voltage volatilities during the increasing of wind power from 0 to $100 \%$ with different conditions.

\section{Introduction}

Recently, with the development of wind power technology, large-scale wind farms are connected in power systems. The connected operating of wind farm will cause voltage quality and voltage stability problems as the randomness and volatility of wind power ${ }^{[1]}$. The reactive compensation is important for voltage regulation in local power network with long distance wind farm connecting ${ }^{[2]}$. The paper ${ }^{[3]}$ gives that the types of wind turbines, the control system and the grid condition can impact the voltage stability of wind power connecting system. The paper ${ }^{[4]}$ show the short-circuit ratio of wind generator connecting node and impedance ratio of trans line are important reasons of the voltage fluctuation and flicker with wind power connecting.

In this paper, the stability of power grid voltage affected by the power fluctuation of wind farm and the improvement effects produced by reactive power compensation device with the wind farm connected to the grid is researched. Firstly, this paper analyses the reactive power problem of wind power with a simple wind farm as example. Secondly, the reactive power compensation equipment of wind farm is introduced. Finally, the PSCAD software for wind farms is used for analyzing the different effects to grid voltage with different reactive power compensation devices and with no reactive power compensation.

\section{Voltage stability of the wind farm integration}

When the wind farm is in heavy load, the active power and the current flowing through the cable and transformer of wind farm are heavy, and the total reactive power consumed by wind farm is larger than the reactive power produced by capacitance to ground. Then the wind farm absorb reactive power from the system as the reactive load, may decrease the voltage of bus and internal node. Doubly-fed induction generator can realize the decoupling control of active and reactive power. Therefore, based on the variable speed of DFIG, the reactive power characteristics of wind farm depend on the control of DFIG. The wind farm composed of DFIG can control that there is no reactive power exchange between the outlet of the wind farm and the power grid. 


\section{Main types of reactive power compensation equipment of wind farm}

At present, the dynamic reactive power compensation device used in wind farm is mainly composed of shunt capacitor bank, static VAR compensator (SVC) and static synchronous compensator (STATCOM).

Shunt capacitor bank. The shunt capacitor bank is presently widely used. The shunt capacitor bank can compensate the reactive power of the system by the switching of the capacitors with a control mode based on its local power factor.

Static VAR compensator (SVC). SVC is currently the most widely used reactive power compensation device which is based on flexible AC transmission system (FACTS) technology. The utility model is the parallel connection of a controllable reactor and a power capacitor (fixed or group switching). The capacitor can emit capacitive reactive power, and the controllable reactor can absorb inductive reactive power. According to the different structure principle, SVC technology can be divided into SSR-Self-saturable reactor, TCR-Thyristor controlled reactor, TSC-Thyristor switched capacitor, TCT, AR and so on ${ }^{[5]}$. With the development of high power electronic device manufacturing technology, TCR/TSC mode has become the mainstream technology of SVC which is used in this paper.

STATCOM. The main circuit of the STATCOM is voltage type bridge and current type bridge. In practical, the voltage type bridge is widely used. Therefore, the working principle of the voltage type bridge is mainly introduced in this article.

The voltage type bridge based on the inverter of voltage source is a reactive power regulating device. The whole device is equivalent to a voltage source, whose voltage can be controlled. This paper assumes its voltage is $U_{1}$, the system voltage is $U_{\mathrm{S}}$, the reactor reactance is $X$ and the output current is as Eq. 1.

$$
\notin=\frac{L_{1}-\sum_{s}}{j X}
$$

Therefore, the complex power absorbed by the device is given in Eq. 2 which named $S$. Generally, STATCOM cannot absorb active power and just makes the active power balanced among the three-phase power. The phase of it is same with system voltage, and the reactive power absorbed by the device is given in Eq. 2 which named $Q$.

$$
S=U_{s}^{\&} \&=U_{s} \frac{L_{s}^{\&^{*}}-U_{1}^{*}}{-j X}, Q=\frac{U_{s}-U_{1}}{X} U_{s}
$$

If the voltage generated by the device is different from the system voltage, the device can emit or absorb reactive power to effectively suppress the voltage fluctuation. When the system voltage drops a lot, STATCOM outputs its maximum instantaneous reactive current. If the voltage cannot be restored, it maintains its maximum reactive current output which can be converted to be a constant current source until the voltage is restored.

\section{The analysis on the power fluctuations of wind power farm to voltage of the grid influences}

In this paper, a double-fed wind power farm of a region is used as an example for studying its interaction with the grid. The line power flow distribution and the interaction of wind turbine group in the wind power farm interior are not studied in this paper. In actual operation currently, because the double-fed wind turbine almost doesn't have the reactive power adjustment ability, the converter of the double-fed wind turbine group doesn't proceed the setting of the reactive power control. The number of the exports of wind power farm step-up switchyard make reactive power exchange with system is not controlled in this simulation. The reactive power compensation device in wind power farm is only regarded as the solution when the voltage of control bus makes mistakes. 
Simulation conditions. Simplifier model with 93 parallel running 1.5MVA double-fed wind turbine groups is used in wind power farm simulating. The output changing rate at the same time of all wind turbines in the wind power farm is $1 \mathrm{p} . \mathrm{u}$. The shunt capacitor group as SVC and STATCOM are used as the reactive power compensation device in wind power farm. The energy of electric is transmitted form the wind turbines in the wind power farm to $66 \mathrm{kV}$ step-up switchyard by a plenty of $10 \mathrm{kV}$ transmission lines. The energy of electric is transmitted to $220 \mathrm{kV}$ step-up switchyard by $220 \mathrm{kV}$ transmission lines, and it is transmitted to a $220 \mathrm{kV}$ substation named $\mathrm{W}$ by $66 \mathrm{kV}$ transmission lines. All transformer capacity is 150MVA. It is assumed that all transformer tap lead is not regulated. The diagram of wind power farm that accessed to the system of a $220 \mathrm{kV}$ substation named $\mathrm{W}$ is shown in Fig. 1.

Simulation conditions. Simplifier model with 93 parallel running $1.5 \mathrm{MVA}$ double-fed wind turbine groups is used in wind power farm simulating.

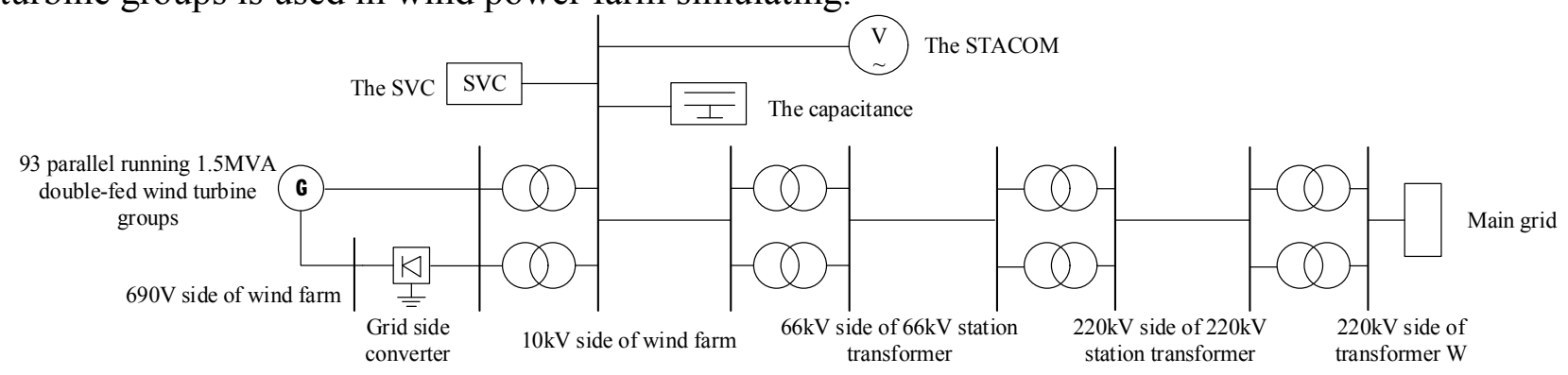

Fig. 1 The power system with wind power farm connecting

The simulation of reactive power compensation device is set groups and parameters as follows.

1. Manual and mechanical switching capacitors are 3 groups with $8 \mathrm{Mvar}$.

2.TSC+TCR is used with $0.5 \mathrm{Mvar} \times 24$ groups of TSC and $12 \mathrm{Mvar} \times 1$ group of TCR.

3.STATCOM capacity is $100 \mathrm{Mvar}$.

The control method of Group 1 is bus voltage of $66 \mathrm{kV}$ side set from 0.99 to $1.03 \mathrm{p} . \mathrm{u}$ in $66 \mathrm{kV}$ step-up switchyard.The control method of Group 2 and Group 3 is bus voltage of $66 \mathrm{kV}$ side set 1.0p.u in $66 \mathrm{kV}$ step-up switchyard.

The simulation of the grid voltage. Because the present method of the wind power generation that accessed to the grid mainly is $220 \mathrm{kV}$ and $66 \mathrm{kV}$ transmission, there are two main simulations of wind power farm which are $220 \mathrm{kV}$ transmission and $66 \mathrm{kV}$ transmission. The buses that are needed to note the voltage which include the wind turbines $690 \mathrm{~V}, 66$ side of $66 \mathrm{kV}$ step-up switchyard, 220 side of $220 \mathrm{kV}$ step-up switchyard and 220 side of substation named Transformer W. Each bus voltage fluctuation curve is from simulating this wind power farm output from 0 to $100 \%$ gradually.

1 Without compensation device, the curve of each bus voltage fluctuation with the output of the wind power farm is shown in Fig. 2.

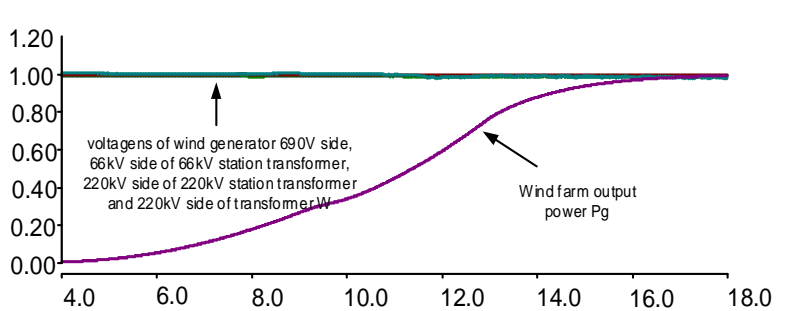

(a) The fluctuation curves with power changing from 0 to $1.2 \mathrm{p} . \mathrm{u}$.

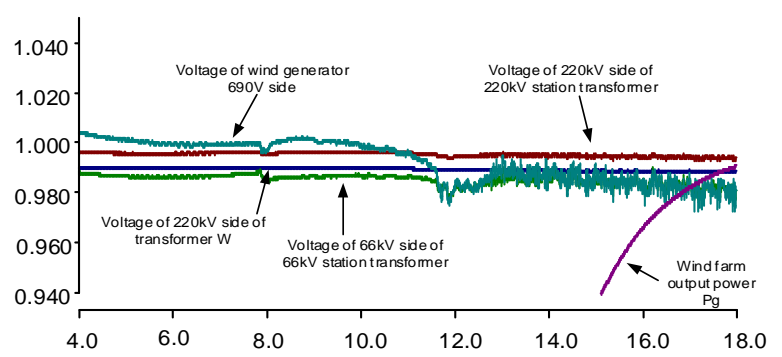

(b) The fluctuation curves with power changing from 0.94 to 1.05 p.u.

Fig. 2 The wind power farm output and the fluctuation curves of bus voltages with no compensation device used

From Fig. 2, in the 4-18s period, of the wind farm output stage changes from 0 to the rated power. The voltage of wind turbine increases with the wind power farm output increases and the consumption of reactive power increases when $12 \mathrm{~s}$ it changes lower. The voltages of the rest buses 
aren't dramatically change. This is due to the absorption of many reactive power from the system side to maintain the voltage.

2 The curve of when the shunt capacitor bank is used as compensation device in the wind power farm each bus voltage fluctuation with the wind power farm output changing is shown in Fig. 3.

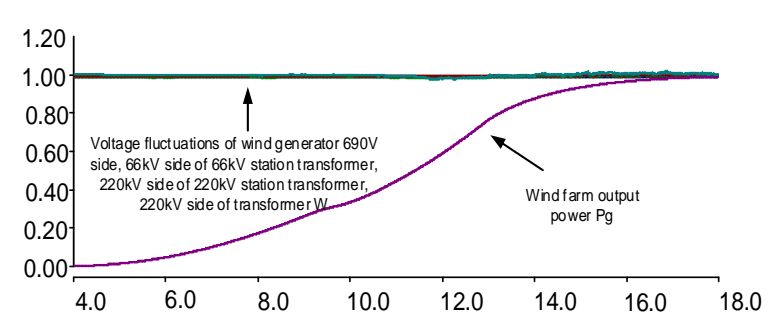

(a) The fluctuation curves with power changing from 0 to $1.2 \mathrm{p} . \mathrm{u}$.

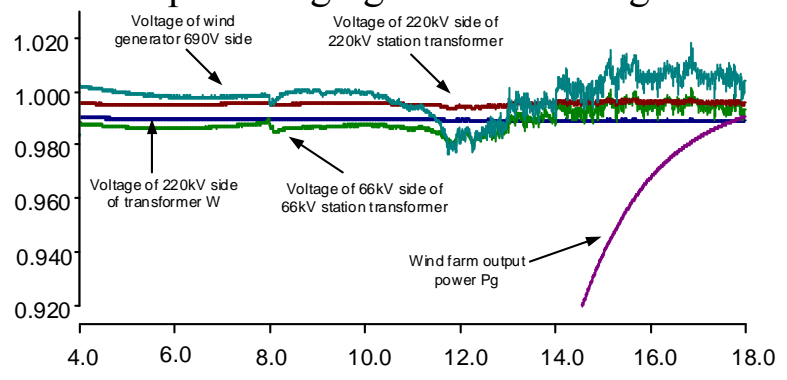

(b) The fluctuation curves with power changing from 0.92 to 1.03 p.u.

Fig. 3 The wind power farm output and the fluctuation curves of bus voltages with shunt capacitor bank used

Before the wind farm output reaches $60 \%$, the line reactive loss is small, the manual switching capacitor cannot move. Then 1 groups of capacitors were put into with the increase of the wind turbine output and the amount of reactive power of lines and transformers. All the capacitor banks were put into while the wind turbine terminal voltage increases up to max 1.02p.u. with the input of the capacitor which can be seen from Fig. 3. Under the action of the shunt capacitor, the voltage of the $66 \mathrm{kV}$ bus is slightly increased, while the other two $220 \mathrm{kV}$ bus voltage is stable.

3 The curves of each bus voltage fluctuation with the wind power farm output changing is shown in Fig. 4 while the static VAR compensator (SVC) is used as compensation device in the wind power farm.

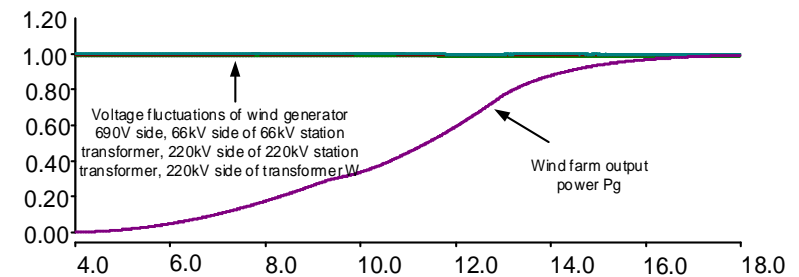

(a) The fluctuation curves with power changing from 0 to 1.2 p.u.

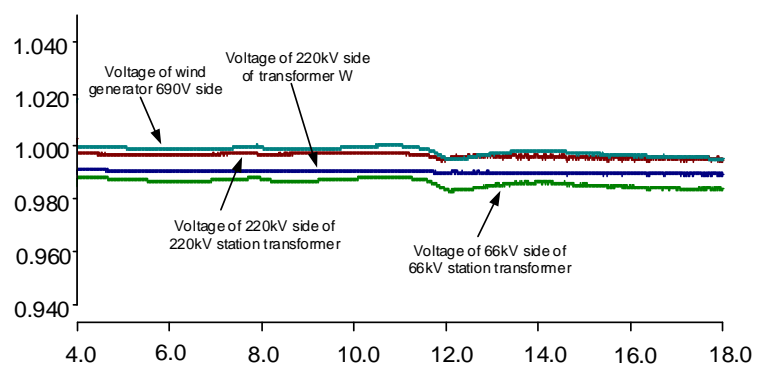

(b) The fluctuation curves with power changing from 0.94 to $1.05 \mathrm{p}$.u.

Fig. 4 The wind power farm output and the fluctuation curves of bus voltages with static VAR compensator (SVC) used

It can be seen from Fig. 4 that when SVC is used as compensator there is no significant change in the voltage of bus with the changing of wind power farm output. Compared with the without compensation device, it raises the outlet voltage level of the wind turbine. Compared with the shunt capacitor bank, it makes exit voltage of the wind turbine and the $66 \mathrm{kV}$ bus voltage are more stable. However, the wind turbine exit voltage and $66 \mathrm{kV}$ voltage is still slightly reduced when it reached $12 \mathrm{~s}$.

4 The curves of each bus voltage fluctuation with the wind power farm output changing is shown in Fig. 5 while the synchronous compensator (STATCOM) is used as compensation device in the wind power farm.

It can be seen from Fig. 5, when STATCOM is used as compensator, with the changing of wind power farm output, the bus voltage is almost unchanged, and each bus voltage level is more stable compared with SVC. 


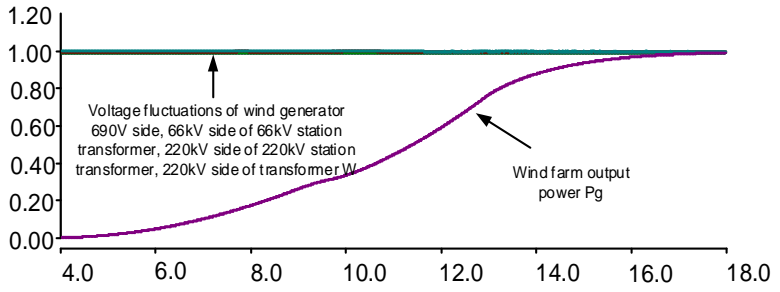

(a) The fluctuation curves with power changing from 0 to $1.2 \mathrm{p} . \mathrm{u}$.

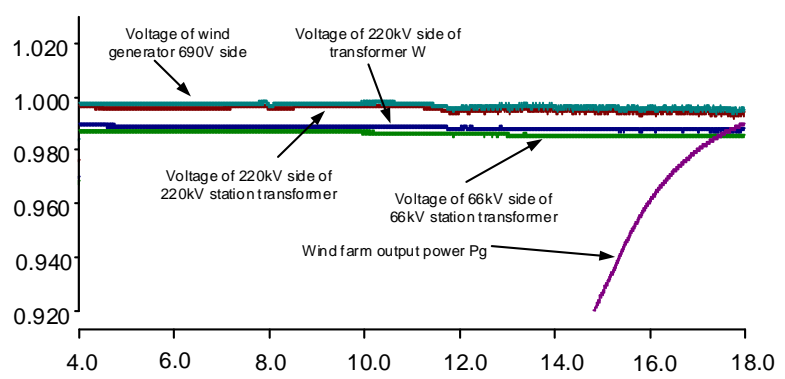

(b) The fluctuation curves with power changing from 0.92 to 1.03 p.u.

Fig. 5. The wind power farm output and the fluctuation curves of bus voltages with synchronous compensator(STATCOM) used

\section{Conclusions}

In this paper, the power grid voltage stability caused by the power fluctuation of the double-fed wind power farm is analyzed, and the improvement effect of different reactive power compensation devices on the grid voltage of stability is analyzed by simulation. The following conclusions can be obtained while the control of the wind power farm and the reactive power have no exchange:

1 When the ratio of wind power farms in the grid is not large, the double-fed wind power farm has negligible effect on the stability of the system voltage when the double-fed wind power farm output increased from 0 to $100 \%$.

2 With the condition of manual and mechanical switched capacitor, static VAR compensator (SVC), static synchronous compensator (STATCOM) configuration, when the double-fed wind power farm output increased from 0 to $100 \%$, STATCOM more obviously improve the voltage stability of the grid effect compared with the other two kinds of compensation device.

\section{References}

[1] M. G. Gracia, M. P. Comech, J. Sallan. Modeling wind farms for grid disturbance studies: Renew-able Energy Vol. 33 (2008), p. 2109-2121

[2] V. Akhmatov, H. Knudsen. An aggregate model of agrid-connected, large-scale, offshore wind farms for power stability investigations-importance of windmill mechanical system: Electrical Power and Energy Systems Vol. 24 (2002), p. 709-717

[3] W. Qiao, R. G. Harley, G. K. Venayagamoorthy, in: Dynamic Modeling of Wind Farms with Fixed-Speed Wind Turbine Ge-nerators, edtied by Power Engineering Society General Meeting Publising, China (2007).

[4] P. Ledesma, J. Usaola, J. L. Transient stability of a fixed speed wind farm: Renewable Energy Vol. 28 (2003), p. 1341-1355

[5] V. Akhmatov, in: Analysis of Dynamic Behavior of Electric Power Systems with Large Amount of Wind Power, edtied by Tec-hnical University of Denmark Publising, April (2003). 